\title{
Editorial note for the special issue: "Selected papers from 12th World Congress on Structural and Multidisciplinary Optimization"
}

\author{
Anton Evgrafov ${ }^{1}$ (D) Byeng Dong Youn ${ }^{2} \cdot \mathrm{Nam} \mathrm{Ho} \mathrm{Kim}^{3}$ \\ Received: 15 March 2018 / Accepted: 16 March 2018 / Published online: 20 April 2018 \\ (C) Springer-Verlag GmbH Germany, part of Springer Nature 2018
}

This special issue of Structural and Multidisciplinary Optimization contains selected works presented at the 12th World Congress on Structural and Multidisciplinary Optimization (WCSMO12) in June 5-9, 2017, in Braunschweig, Germany. Traditionally, the conference is organized on different continents to foster geographical diversity thereby supporting its goal of bringing together optimization researchers and practitioners from all over the world for exchanging ideas and networking. WCSMO12 was organized jointly by Braunschweig University of Technology, University of Wuppertal, and Technical University of Munich under the auspices of the International Society for Structural and Multidisciplinary Optimization (ISSMO).

The selection process for this issue was a mixture of bottom-up and top-down approaches, with members of the SMO community nominating the contributions to the guest editors, who ultimately made the final selection. This decision was based on a variety of factors, including the quality of the work, diversity of the topics, and even practical considerations such as the tight schedule of this issue. As a result of this process, the present issue includes a broad spectrum of contributions ranging from novel methodological development to practical industrial applications of SMO. State-of-the-art topics related to, for example, interplay between SMO and modern fabrication techniques, or to dealing with large scale problems, are well represented.

Responsible Editor: Raphael Haftka

Anton Evgrafov

anton.evgrafov@ntnu.no

1 Department of Mathematical Sciences, Norwegian University of Science and Technology (NTNU), N-7491 Trondheim, Norway

2 Department of Mechanical and Aerospace Engineering, Seoul National University, Gwanak-ro 1, Gwanak-gu Seoul 08826, Republic of Korea

3 Department of Mechanical and Aerospace Engineering, University of Florida, Gainesville, FL 32611, USA
The final list of the contributions is as follows:

1. Simultaneous shape and topology optimization of prestressed concrete beams (https://doi.org/10.1007/ s00158-017-1855-5), O. Amir and E. Shakour

2. Reliability-based design optimization under sampling uncertainty: Shifting design versus shaping uncertainty (https://doi.org/10.1007/s00158-018-1936-0), S. Bae, N.H. Kim, and S.-G. Jang

3. Surrogate modeling in design optimization of structures with discontinuous responses: A new approach for illposed problems in crashworthiness design (https://doi. org/10.1007/s00158-018-1958-7), C. Boursier Niutta, E. J. Wehrle, F. Duddeck, and G. Belingardi

4. Continuum Shape Sensitivity Analysis for FluidStructure Interaction using an Arbitrary LagrangianEulerian Reference Frame (https://doi.org/10.1007/ s00158-018-1947-x), R.A. Canfield and D.A. Sandler

5. Multidisciplinary shape optimization of ductile iron castings by considering local microstructure and material behaviour (https://doi.org/10.1007/s00158-018-1929-z), R. Cenni, J. Olofsson, M. Cova, G. Bertuzzi, K. Salomonsson, and J. Johansson

6. Density Based Topology Optimization of Turbulent Flow Heat Transfer Systems (https://doi.org/10.1007/ s00158-018-1967-6), S.B. Dilgen, C.B. Dilgen, D.R. Fuhrman, O. Sigmund, and B.S. Lazarov

7. Conservative reliability index for epistemic uncertainty in reliability-based design optimization (https://doi.org/10. 1007/s00158-018-1903-9), M. Ito, N. H. Kim, N. Kogiso

8. Multi-phase field topology optimization of polycrystalline microstructure for maximizing heat conductivity (https:// doi.org/10.1007/s00158-018-1965-8), J. Kato

9. Unified topology and joint types optimization of general planar linkage mechanisms (https://doi.org/10.1007/ s00158-017-1887-x), S.W. Kang and Y.Y. Kim

10. Combined Optimization of Part Topology, Support Structure Layout and Build Orientation for Additive 
Manufacturing (https://doi.org/10.1007/s00158-0171877-z), M. Langelaar

11. A Comprehensive Study on Enhanced OptimizationBased Model Calibration Using Gradient Information (https://doi.org/10.1007/s00158-018-1920-8), G. Lee, G. Yi, and B.D. Youn

12. Confidence-Based Reliability Assessment Considering Limited Numbers of Both Input and Output Test Data (https://doi.org/10.1007/s00158-018-1900-z), M.-Y. Moon, H. Cho, K.K. Choi, N. Gaul, D. Lamb, and D. Gorsich

13. Topology Optimization applied to the development of small scale pump (https://doi.org/10.1007/s00158-0181966-7), L.F. Nogueira de Sá, J.S. Romero, O. Horikawa, and E.C.N. Silva

14. Structural optimization with several discrete design variables per part by outer approximation (https:// doi.org/10.1007/s00158-018-1941-3), M. Stolpe and K. Sandal

15. Continuous front propagation-based overhang control for topology optimization with additive manufacturing (https://doi.org/10.1007/s00158-017-1880-4), E. van de Ven, R. Maas, C. Ayas, M. Langelaar, and F. van Keulen
16. Two-scale concurrent topology optimization with multiple micro materials based on principal stress orientation (https://doi.org/10.1007/s00158-018-1916-4), L. Xu and G. Cheng

Acknowledgments There are many people without whom this issue would not be possible. We are thankful to the Structural and Multidisciplinary Optimization community for nominating diverse high quality contributions to be included in this special issue. We are grateful to all the reviewers for volunteering their time, and for their timely and constructive comments. The guest editors would also like to thank SMO Editors Helder C. Rodrigues and Raphael T. Haftka for organizing and supporting this special issue. It goes without saying that even with all the editorial and review effort this special issue could not happen without the extraordinary effort of the conference organizers or the remarkable contributions by the authors.

\section{Publisher's Note}

Springer Nature remains neutral with regard to jurisdictional claims in published maps and institutional affiliations. 